\title{
Effectiveness of Game Learning vs Lecture Method on Knowledge Regarding Biomedical Waste Management among BSc Nursing First-year Students in Kasturba Gandhi Nursing College at Puducherry, India
}

\author{
Umamaheswari Ramesh ${ }^{1}, \mathrm{~K}$ Renuka ${ }^{2}$
}

\begin{abstract}
Background: According to Biomedical Waste (management and handling) Rules, 1998, of India, "Any waste which is generated during the diagnosis, treatment or immunization of human beings or animals or in research activities pertaining thereto or in the production or testing of biological material." The World Health Organization states that $85 \%$ of hospital wastes are actually nonhazardous, whereas $10 \%$ are infectious and $5 \%$ are noninfectious but they are included in hazardous wastes. The objectives of the study was to assess the level of knowledge on biomedical waste (BMW) management, to evaluate the effectiveness of game learning and lecture method on BMW management and to compare the effectiveness of game learning vs. the lecture method on BMW management among BSc nursing first-year students.

Materials and methods: The quantitative research approach, true experimental research design was adopted for the study. The study was conducted among BSc nursing first-year students at Kasturba Gandhi Nursing College, Puducherry. Totally, 90 samples were selected with 45 each in group I and group II by the random sampling technique (lottery method). The demographic data and the structured knowledge questionnaire on BMW management were collected from the students.

Results: The result revealed that, in group I, the pre- and posttest mean values were 9.47 and 21 , respectively, and standard deviation values were 2.51 and 3.15 , respectively. In group II, the pre- and posttest mean values were 9.49 and 18.89 , respectively, and standard deviation values were 2.48 and 4.47 , respectively. While comparing pretest and posttest according to the Mann-Whitney test, the pretest value was 0.042 and the $p$ value was 0.966 , and the posttest value was 2.589 and the $p$ value was 0.011 . While comparing group I and group II, the obtained Wilcoxon ( $t$ test) values were 23.444 and 15.579 . It indicates that there was a variation in the level of knowledge in group I and group II. It shows that game learning was effective than the lecture method of the level of knowledge.

Conclusion: The study findings reveal that game learning $(p<0.001)$ was effective than the lecture method on the level of knowledge regarding BMW management among BSC nursing first-year students. It indicates that there was a variation in the level of knowledge in group I and group II. It shows that game learning was more effective than the lecture method on the level of knowledge.

Keywords: Biomedical waste management, Game learning, Knowledge, Lecture method.

Pondicherry Journal of Nursing (2019): 10.5005/jp-journals-10084-12128
\end{abstract}

\section{INTRODUCTION}

Hospitals are centers of cure and also the important centers of infectious waste generation. Effective management of biomedical waste (BMW) is not only a legal necessity but also social responsibility. ${ }^{1}$ All hospitals, nursing homes, clinics, primary health centres (PHCs), community health centers, and laboratories have to ensure safe disposal and environmentally sound management of waste produced by them as specified in rules for proper BMW disposal. ${ }^{2}$ The head of healthcare facilities should take responsibilities to safeguard the health workers involved in handling, transportations, and disposal of BMW besides ensuring safety to the community and environment. ${ }^{3}$ According to Biomedical Waste (management and handling) Rules, 1998, of India, "Any waste which is generated during the diagnosis, treatment or immunization of human beings or animals or in research activities pertaining there to or in the production or testing of biological." ${ }^{\prime 4}$

The WHO reports that $85 \%$ of hospital waste are nonhazardous, $10 \%$ infectious, and the remaining $5 \%$ are noninfectious but hazardous chemical, pharmaceutical, or radioactive. The wastes are potential sources of infection transmission, ${ }^{5}$ especially hepatitis B and C, HIV, and tetanus; approximately $1.4 \mathrm{~kg}$ per bed
${ }^{1}$ Department of Obstetrics and Gynecology Nursing, Kasturba Gandhi Nursing College , Sri Balaji Vidyapeeth Deemed University, Puducherry, India

${ }^{2}$ Department of Medical Surgical Nursing, Kasturba Gandhi Nursing College, Sri Balaji Vidyapeeth Deemed University, Puducherry, India

Corresponding Author: Umamaheswari Ramesh, Department of Obstetrics and Gynecology Nursing, Kasturba Gandhi Nursing College, Sri Balaji Vidyapeeth Deemed University, Puducherry, India, Phone: +91 9965228299, e-mail: umamaheswarir@kgnc.ac.in

How to cite this article: Ramesh U, Renuka K. Effectiveness of Game Learning vs Lecture Method on Knowledge Regarding Biomedical Waste Management among BSc Nursing First-year Students in Kasturba Gandhi Nursing College at Puducherry, India. Pon J Nurs 2019;12(3):63-67.

Source of support: Nil

Conflict of interest: None

per day waste is generated in Indian hospitals and as high as 4.5 kg per bed per day in developed country like the United States and approximately $15 \%$ of waste is hazardous and $85 \%$ of waste is nonhazardous. Out of $15 \%$ of hazardous waste, $5 \%$ is noninfective 
and $10 \%$ is infective. About $15-35 \%$ of hospital waste is regulated as infectious waste. This range is dependent on the total amount of waste generated. ${ }^{5-7}$

Hospital waste is potential health hazard to the healthcare workers and public. The problems of the waste disposal in the hospitals and other healthcare institutions have become issues of increasing concern. ${ }^{8}$ The basic elements are to recognize the waste, identify where waste was generated and determine the cause of generation, and plan for disposal of the waste in a scientific manner, so as to render it environmentally nonhazardous and eliminate the source of infection., ${ }^{9,10}$

Biomedical waste should be segregated into color-coded bags or containers at source, and its processing and proper disposal should be of great concern to both medical professionals and the general public. ${ }^{11}$ Proper segregation as well as disposal of waste products in hospitals is essential. It can also lead to health risks in the patients and the caregivers. ${ }^{12-16}$

A descriptive study was conducted to evaluate the level of knowledge regarding BMW management among nurses in Christian Mission Hospitals at Madurai. The study findings revealed that among 30 nurses, 23 (77\%) had adequate knowledge, 7 (23\%) had moderate adequate knowledge, and none of them had inadequate knowledge. ${ }^{17}$ A cross-sectional study was done to assess the level of knowledge about BMW management among medical students. A total of 127 medical students of seventh semester MBBS were from Sri Venkateswara Medical College, Tirupati. The study concluded that awareness campaigns and classes could be conducted to enhance knowledge about safe handling and disposal of BMW for potential practical applications among medical students. ${ }^{18}$

There is a need to up-to-date their knowledge and practices of BMW management. The investigator thought that awareness through a teaching program is an excellent way for nursing students to prepare themselves with the latest information on BMW management skills and techniques to help them function in hospitals effectively. So, assessing the knowledge among nursing students (as future nursing professionals) by the lecture method and the gaming method creates awareness among students regarding the importance of BMW management. ${ }^{19-25}$

\section{Objectives}

- To assess the level of knowledge on BMW management among BSc nursing first-year students

- To evaluate the effectiveness of game learning and the lecture method on BMW management among BSc Nursing first-year students

- To compare the effectiveness of game learning vs. lecture method on BMW management among BSc nursing first-year students

- To find out association between the level of knowledge on BMW management and selected demographic variables

\section{Hypotheses}

$\mathrm{H} 1$ : There is a significant difference in the level of knowledge regarding BMW management among BSc nursing first-year students.

$\mathrm{H} 2$ : There is a significant difference in the effectiveness of game learning vs lecture method on the level of knowledge regarding BMW management among BSc nursing first-year students.
H3: There is a significant association between the level of knowledge on BMW management and selected demographic variables.

\section{Materials and Methods}

The quantitative research approach was used. The research design used in this study was true experimental (two group pretest posttest design) research design. A total of 90 samples were selected with 45 each in group I and group II by the random sampling technique (lottery method). By using the structured knowledge questionnaire, data were collected from BSc nursing first-year students by pretest. Group I received game learning and group II received the lecture method on the level of knowledge regarding BMW management. After 1 week, posttest was conducted by same questionnaire to assess the effectiveness of game learning vs lecture method on the level of knowledge regarding BMW management among BSC nursing first-year students. Data were analyzed by both descriptive (mean, frequency, percentage, and standard deviation) and inferential statistics (Chi-square test and Wilcoxon signed-rank test).

\section{Results}

With regard to age, majority of samples, 24 (53.3\%) in group I, 23 $(51.1 \%)$ in group II, belong to the age group of 18 years. Regarding gender, most of the samples, 26 (57.8\%) in group I, 29 (64.4\%) in group II, belong to the gender of female. In regard of family type, majority of samples, 30 (66.7\%) in group I, 25 (55.6\%) in group II, belong to nuclear family. Regarding religion, majority of samples, 42 (93.3\%) in group I, 34 (75.6\%) in group II, belongs to religion of Hindu. Regarding living area, majority of samples, 27 (60.0\%), in group I belong to urban area, and 25 (55.6\%) in group II belong to rural area. Regarding source of information, majority of the samples, 19 (40.2\%) in group I, 27 (60.0\%) in group II, got information by their friends/relatives.

Figure 1 shows the distribution of the level of knowledge in BSC nursing first-year students in group I and group II during pretest and posttest. In pretest out of 45 samples in group I, 40 (88.9\%) had inadequate knowledge, 5 (11.1\%) had moderately adequate knowledge, and none of them had adequate knowledge. In posttest out of 45 samples in group II, none of them had inadequate knowledge, 28 (62.2\%) had moderately adequate knowledge, and $17(57.8 \%)$ had adequate knowledge. In pretest out of 45 samples in group II, 43 (95.6\%) had inadequate knowledge, 2 (4.4\%) had moderately adequate knowledge and none of them had adequate knowledge. In posttest out of 45 samples in group II, 7 (15.6\%) had inadequate knowledge, $26(57.8 \%)$ had moderately adequate knowledge, and 12 (26.7\%) had adequate knowledge.

Figure 2 shows that the pretest and posttest mean and standard deviation of level of knowledge in group I and group II. In group I, the pre- and posttest mean values were 9.47 and 21.00, respectively, and standard deviation values were 2.51 and 3.15 , respectively. The obtained $t$ test value was 23.444 . In group II, the pre- and posttest mean values were 9.49 and 18.89 , respectively, and standard deviation values were 2.48 and 4.47 , respectively. The obtained $t$ test value was 15.579 . It was highly statistically significant at $p<0.001$ level. There is significant difference between pretest and posttest values of the level of knowledge in group I and group II. This results show that there is a significant difference in the level of knowledge regarding BMW management among BSC nursing first-year students. Hence, hypothesis $(\mathrm{H} 1)$ was accepted. 


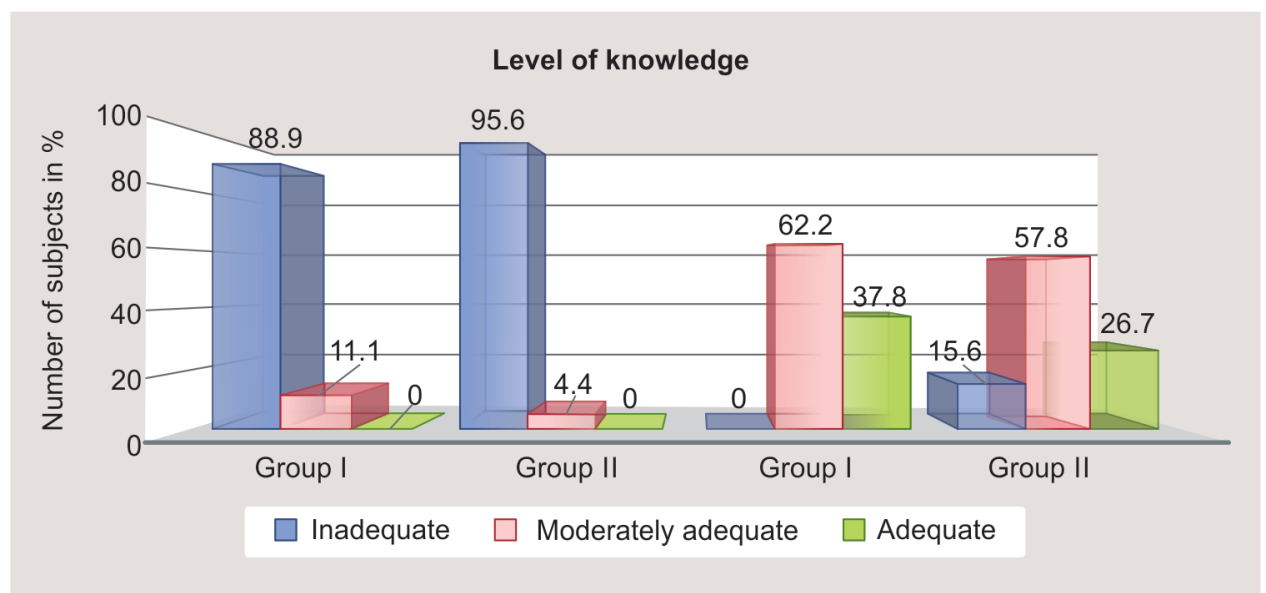

Fig. 1: Percentage distribution of level of knowledge

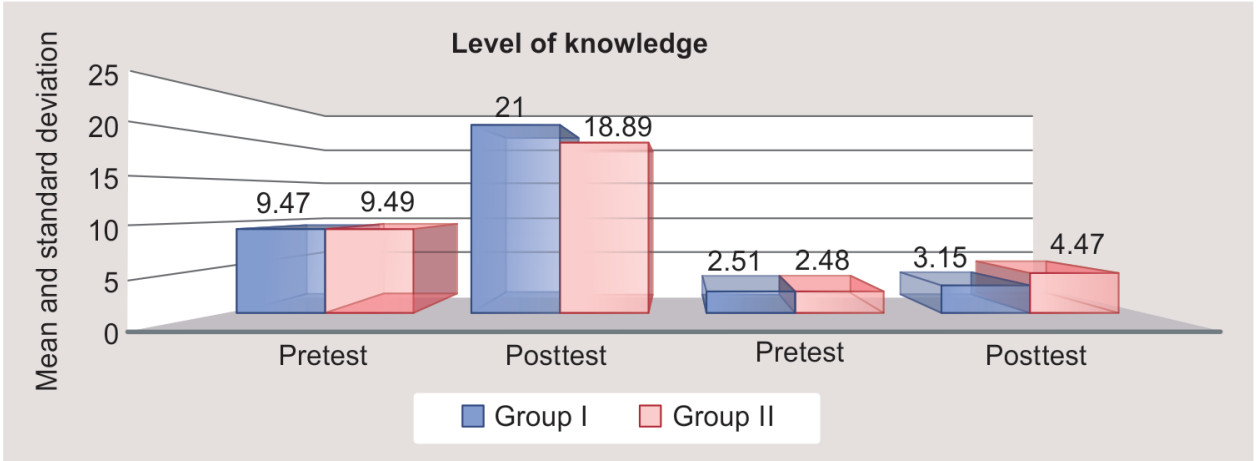

Fig. 2: Comparison of pre- and posttest level of knowledge regarding biomedical waste management in group I and group II

Table 1: Effectiveness of game learning vs. lecture method on the level of knowledge regarding biomedical waste management in group I and group II

\begin{tabular}{|c|c|c|c|c|c|c|c|c|}
\hline \multirow[b]{2}{*}{ Group } & \multicolumn{3}{|c|}{ Pretest } & \multicolumn{3}{|c|}{ Posttest } & \multirow[b]{2}{*}{ t test } & \multirow[b]{2}{*}{$p$ value } \\
\hline & Mean & $\begin{array}{l}\text { Standard } \\
\text { deviation }\end{array}$ & $\begin{array}{l}\text { Standard } \\
\text { mean error }\end{array}$ & Mean & $\begin{array}{l}\text { Standard } \\
\text { deviation }\end{array}$ & $\begin{array}{l}\text { Standard } \\
\text { mean error }\end{array}$ & & \\
\hline Group I & 9.47 & 2.51 & 0.37 & 21 & 3.15 & 0.47 & 23.44 & $<0.001$ \\
\hline Group II & 9.49 & 2.48 & 0.37 & 18.89 & 4.47 & 0.67 & 15.579 & $<0.001$ \\
\hline Mann-Whitney $t$ test & \multicolumn{3}{|c|}{0.042} & \multicolumn{3}{|c|}{2.589} & & \\
\hline$p$ value & \multicolumn{3}{|c|}{0.966} & \multicolumn{3}{|c|}{0.011} & & \\
\hline
\end{tabular}

Highly statistically significant at $p<0.001$

Table 1 shows that the effectiveness of game learning and the lecture method on level of knowledge regarding BMW management among BSc nursing first-year students in pretest and posttest by using mean and standard deviation.

In group I, the pre- and posttest mean values were 9.47 and 21 , respectively, and standard deviation values were 2.51 and 3.15, respectively. In group II, the pre- and posttest mean values were 9.49 and 18.89 , respectively, and standard deviation values were 2.48 and 4.47 , respectively. While comparing pretest and posttest according to the Mann-Whitney test, the pretest value was 0.042 and the $p$ value was 0.966 , the posttest value was 2.589 and the $p$ value was 0.011 . While comparing group I and group II, the obtained Wilcoxon ( $t$ test) values were 23.444 and 15.579. It indicates that there was a variation in the level of knowledge in group I and group II. It shows that game learning was effective than the lecture method of the level of knowledge. Hence, the stated hypothesis $\left(\mathrm{H}_{2}\right)$ was accepted.
In association, there is no significant association between the level of knowledge and the demographic variables like age, gender, family type, religion, living area, and source of information. Hence, the stated hypothesis $(\mathrm{H} 3)$ was rejected.

\section{Discussion}

This study was conducted to evaluate the effectiveness of game learning vs. lecture method on knowledge regarding BMW management among BSc nursing first-year students in KGNC at Puducherry. True experimental design was adopted for the study. The population of the study was only BSc nursing first-year students. A total of 90 samples were selected by the simple random sampling technique, 45 in each group. Pretest was done by structured knowledge questionnaires. Group I received game learning and group II received the lecture method. After intervention, posttest was done by structured knowledge questionnaires. 
The first objective of the present study was to assess the level of knowledge on BMW management among experimental group I and group II. In pretest out of 45 samples in group I, 40 (88.9\%) had inadequate knowledge, 5 (11.1\%) had moderately adequate knowledge, and none of them had adequate knowledge. In posttest out of 45 samples in group II, none of them had inadequate knowledge, 28 (62.2\%) had moderately adequate knowledge, and $17(57.8 \%)$ had adequate knowledge. Hence, the stated hypothesis $\left(\mathrm{H}_{1}\right)$ was accepted.

The second objective of the study was to evaluate the effectiveness of game learning vs. lecture method on BMW management among BSc nursing first-year students. In group I, the pre- and posttest mean values were 9.47 and 21.00 , respectively, and standard deviation values were 2.51 and 3.15 , respectively. The obtained $t$ test value was 23.444 . It was highly statistically significant at $p<0.001$ level. There is significant difference between pretest and posttest values of the level of knowledge in group I. In group II, the pre- and posttest mean values were 9.49 and 18.89 , respectively, and standard deviation values were 2.48 and 4.47, respectively. The obtained $t$ test value was 15.579 . It was highly statistically significant at $p<0.001$ level. There is significant difference between pretest and posttest values of the level of knowledge in group II. This results show that there is a significant difference in the level of knowledge regarding BMW management among BSc nursing first-year students. Hence the stated hypothesis $\left(\mathrm{H}_{1}\right)$ was accepted.

The third objective of the study was to compare the effectiveness of game learning vs. lecture method among BSc nursing first-year students. In group I, the pre- and posttest mean values were 9.47 and 21 , respectively, and standard deviation values were 2.51 and 3.15 , respectively. In group II, the pre- and posttest mean values were 9.49 and 18.89 , respectively, and standard deviation values were 2.48 and 4.47 , respectively. While comparing pretest and posttest according to the Mann-Whitney test, the pretest value was 0.042 and the $p$ value was 0.966 , the posttest value was 2.589 and the $p$ value was 0.011 . While comparing group I and group II, the obtained Wilcoxon ( $t$ test) values were 23.444 and 15.579 . It indicates that there was a variation in the level of knowledge in group I and group II. It shows that game learning was effective than the lecture method of the level of knowledge. Hence the stated hypothesis $\left(\mathrm{H}_{2}\right)$ was accepted.

The fourth objective of the study was to find out the association between the level of knowledge on BMW management among nursing students and selected demographic variables. There is no significant association between the level of knowledge and the demographic variables like age, gender, family type, religion, living area, and source of information. Hence the stated hypothesis $\left(\mathrm{H}_{3}\right)$ was rejected.

\section{ConcLusion}

The main conclusion of the present study reveals that BSc nursing first-year students show the effectiveness of game learning and lecture method on the level of knowledge regarding BMW management in pretest and posttest by using mean and standard deviation. In group I, the pre- and posttest mean values were 9.47 and 21 , respectively, and standard deviation values were 2.51 and 3.15 , respectively. In group II, the pre- and posttest mean values were 9.49 and 18.89 , respectively, and standard deviation values were 2.48 and 4.47 , respectively. While comparing pretest and posttest according to the Mann-Whitney test, the pretest value was 0.042 and the $p$ value was 0.966 , and the posttest value was 2.589 and the $p$ value was 0.011 . While comparing group I and group II, the obtained Wilcoxon ( $t$ test) values were 23.444 and 15.579 . It indicates that there was a variation in the level of knowledge in group I and group II. It shows that game learning was effective than the lecture method of the level of knowledge on BMW management.

\section{Recommendations}

- The study can be replicated with a large sample for better generalization.

- More studies can be conducted on improving the level of knowledge using different teaching methods.

- Studies can be done to assess the knowledge and practice of student nurses on improving the level of knowledge regarding BMW management.

- Comparison can be done to evaluate the effectiveness of different teaching methods with other nursing interventions among BSc nursing first-year students.

\section{References}

1. Sharma AK. Biomedical waste management rules. Bhopal: Suvidha, Law House; 1998. pp. 102-150.

2. Veera MP, Kumar KS. Impact of training on biomedical waste management - A study and analysis excel. Int J Multidiscip Manage 2016;6(2):1-3.

3. Mathur P, Patan S, Shobhawat S. Need of biomedical waste management system in hospitals -an emerging issue - A review. Current World Environ 2012;7(1):117-124. DOI: 10.12944/ CWE.7.1.18Available from http://www.cwejournal.org/?p=1960.

4. Baveja G, Aggarwal MS. Hospital waste management. 5th ed. 2000. pp. 485-486.

5. Ramesh Babu B, Parande AK, Rajalakshmi R, Suriyakala P, Volga M. Management of biomedical waste in india and other countries. J Environ App Sci 2009;4(1):65-78.

6. Tenglikar PV, Kumar GA, Kapate R, Reddy S, Vijayanath V. Knowledge, attitude, and practices of health care waste management amongst staff of nursing homes of Gulbarga city. J Pharm Biomed Sci 2012;19(19):1-3.

7. INCLEN Program Evaluation Network (IPEN) study group, New Delhi, India. A study conducted on biomedical waste management:situational analysis \& predictors of performances in 25 districts across 20 indian states. Indian J Med Res 2014;139(1): 141-153.

8. Prabhakar Rao VV, Uday Kiran G. Biomedical waste generation and management in various hospitals. J Adv Res Sci Engin 2014;3(11): 2319-8354. Available from: http://www.ijarse.com.

9. Preeba MP, Priya K, Rajalakshmi G, Reeja Mary R. Knowledge of nursing students on biomedical waste management. 2009. pp. 10-14.

10. Hassan MM, Ahmed SA, Rahman KA, Biswas TK. Pattern of medical waste management: existing scenario in Dhaka city, Bangladesh. BMC Public Health 2008;3(7):36-40. DOI: 10.1186/1471-24588-36.

11. Arunkumar $S$, Muthukumar RS. Biomedical waste in dental clinics. SRM Uni J Dent Sci 2011;2(2):118-120.

12. Khanam R, Chorai G, Bhattacharaya K, Swain A, Joseph NM. Effect of gaming on knowledge regarding biomedical waste management. J Nurs 2017;7(2):6-13.

13. Lakbala P, Lakbala M. Knowledge, attitude and practice of hospital staff management. Waste Manag Res 2013;31(7):729-732. DOI: 10.1177/0734242X13484190.

14. Vallepalli C, Rao KU, Reddy KT, Sekhar KC, Gogineni SS, Deotale. Knowledge and practice of hospital waste management among nursing staff of tertiary care centre hospital. Indian J Public Health 2017;8(3):159-160. 
15. Mohammadi P, Rahimi S, Dashtaleh T, Sohrabi Y. Studying the level of knowledge, attitude, and performance among personnel of doctor. Annal Tropical Med Public Health 2017;10(3):612.

16. Jadhav J, Thangaraj S, Dsouza L, Rao A. Assessment of educational intervention on biomedical waste management among government nursing college students. Int J 2015;4(3):726-729. DOI: 10.5455/ ijmsph.2015.07012015150.

17. Suganya P. Knowledge on biomedical waste management among nurses working in hospital at Madurai. International Health Science and Research 2016;7:229-233.

18. Ajai S, Nath SR. Knowledge, attitude and practices of biomedical waste management amongst staff of institutional trauma center level II. Int J Res Health Sci 2013;1(2):62-68.

19. Srivastava J. Knowledge regarding biomedical waste management among the staff nurses. Int J Sci Res 2016;5(7):2319-7064.

20. Dhananjay K, Vaishali K, Shanmugasamy K, Ancy A. Impact of intervention on awareness of biomedical waste disposal among medical students. J Annal Pathol Laborat Med 2017;4(3): 231-333.

21. Ruby R. A study on effectiveness of planned teaching programme on biomedical waste management among staff nurses working in a selected hospital at Mangalore. Medical Surgical Nursing 2017;3(2):351-352. Available from: http://hdl.handle. net/123456789/2819.

22. Jadhav. J. Effectiveness of educational intervention on knowledge and practice among bio-medical waste handlers. Int J Sci Res 2014;3(5):2319-7064.

23. Saranya D. Lecture method vs panel discussion on knowledge regarding selected communicable disease. 2014. 19-25.

24. Sawatsky AP. Lecture method vs panel discussion on knowledge regarding selected communicable disease. 2014. 15-17.

25. Ngaraju B, Padmavathi GV, Puranik DS, Shantharaj MP, Sampulatha SP. Knowledge and practice on biomedical waste management among the health care providers working in PHC. Int J Med Biomed Res 2013;2(1):547-550. 